\title{
Correlation of serum aspartate aminotransferase level to platelet count ratio index with non-alcoholic fatty liver disease activity score
}

\author{
Dulal Chandra Das, Shahinul Alam, Sheikh Mohammad Noor-E-Alam, Mohammed Kamal, \\ Forhadul H. Mollah and Mamun-Al-Mahtab
}

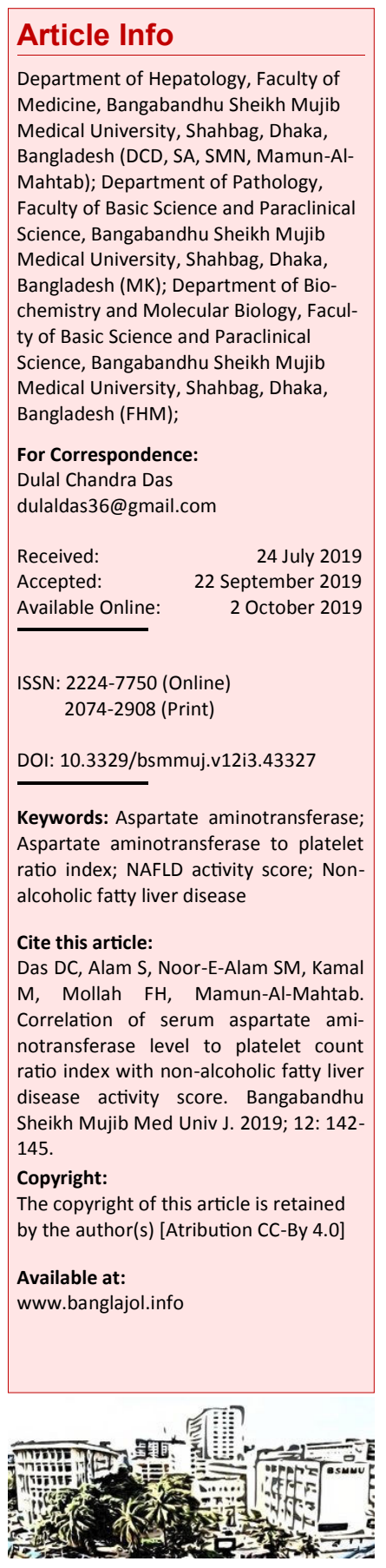

\section{Abstract}

In case of non-alcoholic fatty liver disease, the ratio of serum aspartate aminotransferase (AST) level to platelet count index has been proposed as a non-invasive and readily available tool for the assessment of non-alcoholic steatohepatitis. The study was conducted on 50 non-alcoholic fatty liver disease patient ( 25 non-alcoholic steatohepatitis and 25 simple steatosis). The mean ( \pm SD) serum AST level in the non-alcoholic steatohepatitis group was $55.2 \pm 30.1 \mathrm{IU} / \mathrm{L}$ whereas in simple steatosis group, it was $33.6 \pm 20.0 \mathrm{IU} / \mathrm{L}$. The mean platelet count in the non-alcoholic steatohepatitis group was $303.1 \pm 68.7 \times 10^{9} / \mathrm{L}$ whereas in the simple steatosis group, it was 327.8 $\pm 66.8 \times 10^{9} / \mathrm{L}$. The mean AST platelet ratio index (APRI) score in non-alcoholic steatohepatitis group was $0.5 \pm 0.3$ and in the simple steatosis group, it was $0.3 \pm 0.2$. In conclusion, the APRI was significantly higher in the non-alcoholic steatohepatitis group than the simple steatosis group.

\section{Introduction}

Non-alcoholic fatty liver disease is a metabolic disorder characterized by excessive triglyceride accumulation in the hepatocytes. 1 It is an acquired metabolic stress-induced liver disease associated with insulin resistance and genetic susceptibility, sharing histological similarities with alcoholic liver disease in the absence of substantial alcohol consumption or other causes of liver disease. 2 Two broad types are recognized. The simple steatosis is typically stable while the non-alcoholic steatohepatitis is characterized by significant cell injury and the potential for progression to cirrhosis. 3 Nonalcoholic fatty liver disease consists of a wide spectrum of conditions, ranging from simple steatosis to non-alcoholic steatohepatitis which can progress to cirrhosis and hepatocellular carcinoma. $\underline{4}$

The fatty liver may be diagnosed if the liver echogenicity exceeds that of renal cortex and spleen and there is attenuation of the ultrasound wave, loss of definition of the diaphragm, and poor delineation of the intrahepatic architecture. .5

The serum alanine aminotransferase (ALT) is a marker of hepatic steatosis or hepatitis 6 and non-alcoholic steatohepatitis has been associated with slight elevation of liver enzymes like ALT and gamma-glutamyl transferase. $\frac{7}{-}$ The patient typically presents with asymptomatic serum ALT elevation of 2-3 times than the normal. 8 This was also explored by Pulzi et al. (2011), 9 where the majority had mild elevation but less than 5 times the upper normal limit and exists in all degree of non-alcoholic fatty liver disease. But Alam et al. (2013) showed the serum ALT levels were not able to predict the non-alcoholic steatohepatitis. $\underline{10}$

The aspartate aminotransferase (AST) is a hepatic transaminase that plays a role in the diagnosis of steatohepatitis. Up to $3.6 \%$ of people in the United States have asymptomatic increase in aspartate aminotransferase. $\underline{11}$

The AST/ALT ratio is approximately 0.8 in normal subject. The AST level is greater than the ALT level in alcoholic hepatitis and a ratio greater than 2:1 is highly suggestive of this disorder. A ratio $>1.0$ may also suggest the presence of cirrhosis in patients with chronic viral hepatitis. $\underline{12}$

Excess deposition of fat in the liver is associated with an elevated serum gamma-glutamyl transferase and insulin resistance. $\underline{13}$ An increased gamma-glutamyl transferase level is a risk factor for advanced fibrosis in non-alcoholic fatty liver disease. $\underline{14}$

Reduced platelet count or thrombocytopenia is a common finding in advanced stages of all the chronic hepatic diseases, and the platelet count is clinically important to predict the status of hepatic fibrosis in patients with chronic hepatic 


\section{diseases. $\underline{15}$}

The AST to platelet ratio index was originally developed to predict the advanced fibrosis in patient with chronic hepatitis $\mathrm{C}$ infection but was subsequently investigated for the same task in patient with non-alcoholic fatty liver disease. $\underline{16-18}$ The AST to platelet ratio index score yields the highest accuracy. Because AST to platelet ratio index consists of the platelet count and AST, $\underline{16}$ its accuracy is presumably attributable to the predictive value of AST for fibrosis severity.

Liver biopsy remains the gold standard for the diagnosis of non-alcoholic steatohepatitis, which allows us to differentiate the simple steatosis from non-alcoholic steatohepatitis. 19 There are practical limitations, including invasiveness, rare but potentially life-threatening complications like risk of bleeding, allergic reaction caused by local anesthetics, advanced age, poor acceptability, sampling variability and cost. Furthermore, due to the epidemic proportion of individuals with nonalcoholic fatty liver disease worldwide, liver biopsy evaluation is impractical, and non-invasive assessment for the diagnosis of non-alcoholic steatohepatitis and fibrosis is needed.

The AST platelet ratio index (APRI) score, derivative of the AST and platelet count, is a useful tool for non-invasive and available marker for assessment of non-alcoholic steatohepatitis.

\section{Materials and Methods}

The study was carried out for a period of 2 years on the patients of non-alcoholic fatty liver disease attended the department. Fifty non-alcoholic fatty liver disease patients were selected for biochemical parameters, liver biopsy and non-alcoholic fatty liver disease activity score (NAS) evaluation considering the exclusion and inclusion criteria. Nonalcoholic fatty liver disease activity score was constructed according to Kleiner et al. (2005)르 with steatosis (0-3), lobular inflammation (0-3), hepatocellular ballooning (0-2) and a separate fibrosis staging (0-4). The proposed non-alcoholic fatty liver disease activity score was the sum of steatosis, lobular inflammation, and hepatocellular ballooning. Non-alcoholic fatty liver disease activity score is a good scoring system. Non-alcoholic fatty liver disease activity score of greater than or equal to 5 correlated with diagnosing of non-alcoholic steatohepatitis and the biopsy with scoring of 1 to 4 was diagnosed as simple steatosis fatty liver. Patient's inclusion criteria were the ultrasonographical evidence of fatty liver and patients of 18 to 60 years of age. Exclusion criteria were the significant alcohol intake (>30 g/day- male; $>20$ g/dayfemale), $\underline{21}$ viral hepatitis (hepatitis B virus, hepatitis $C$ virus), Wilson's disease, autoimmune liver diseases, hereditary hemochromatosis, primary biliary cirrhosis, cirrhosis of liver, pregnancy, comorbid conditions (chronic obstructive airway disease, chronic kidney disease, cardiac failure), hypothyroidism, consumption of drugs causing fatty change in the liver (steroid, oral contraceptive pill, tamoxifen, amiodarone, diltiazem, protease inhibitor). In the American Association for the Study of Liver Diseases Practice Guideline 2018, significant alcohol consumption can be defined as $>21$ standard drinks per week in men and >14 standard drinks per week in women over 2 years period preceding baseline liver histology. The liver biopsy was done by Trucut liver biopsy needle $14 \mathrm{~F}$ $15 \mathrm{~cm}$. The tissue was processed at the Department of Pathology, by standard protocol in automatic tissue processor (BAVIMED 2050, BAVIMED Laborgeneratebau $\mathrm{GmBH}$, Birkeau, Germany). The processed tissue was then properly embedded on the melted paraffin for making blocks and sections. The sections were stained with hematoxylin and eosin for microscopic examination.

The AST was measured by CI 4100 Architect plus autoanalizer (Abbott, USA) by liquid reagent pyridoxal-5 $\square$ - phosphate. Platelet count were done in autoanalizer at the Department of Clinical Pathology.

After receiving the liver biopsy report, they were grouped as non-alcoholic steatohepatitis and simple steatosis. Consecutive 25 non-alcoholic steatohepatitis patients and 25 simple steatosis patients confirmed by liver biopsy were included in this study.

\section{Statistical analysis}

All data were presented as mean \pm SD and were analyzed by SPSS (version 16). The qualitative data were analyzed by Chi-squared test and the quantitative data were analyzed by student's t-test. Performance of the test were assessed by sensitivity and specificity test. Statistically significant result were considered when $p$ value $<0.05$.

\section{Results}

The mean $( \pm$ SD) AST level in the non-alcoholic steatohepatitis group were $55.2 \pm 30.1 \mathrm{IU} / \mathrm{L}$ whereas in simple steatosis group it was $33.6 \pm 20 \mathrm{IU} / \mathrm{L}$ (Table I). The mean AST was statistically significant $(p<0.05)$ between the two groups. The mean platelet count in the non-alcoholic steatohepatitis group was $303.1 \pm 68.7 \times 10^{9} / \mathrm{L}$ and in simple steatosis group was $327.8 \pm 66.8 \times 10^{9} / \mathrm{L}$.

The APRI score in non-alcoholic steatohepatitis group was $0.5 \pm 0.3$ whereas it was $0.3 \pm 0.2$ in simple steatosis group (Table II). It was significantly higher in the non-alcoholic steatohepatitis group than the simple steatosis group $(\mathrm{p}=0.009)$. 
Table I

\begin{tabular}{|c|c|c|c|}
\hline \multicolumn{4}{|c|}{ Clinical and laboratory characteristics of patients } \\
\hline Variables & $\begin{array}{l}\text { Non-alcoholic } \\
\text { steatohepatitis } \\
\quad(n=25)\end{array}$ & $\begin{array}{c}\text { Simple steato- } \\
\text { sis } \\
(\mathrm{n}=25)\end{array}$ & $\mathrm{p}$ value \\
\hline & Mean \pm SD & Mean \pm SD & \\
\hline Age (years) & $41.8 \pm 10.7$ & $39.7 \pm 7.5$ & $0.425^{\mathrm{ns}}$ \\
\hline Body weight (kg) & $65.6 \pm 8.6$ & $63.3 \pm 9.7$ & $0.444^{\mathrm{ns}}$ \\
\hline Height (cm) & $159.2 \pm 9.1$ & $157.7 \pm 8.3$ & $0.545^{\text {ns }}$ \\
\hline Body mass index $\left(\mathrm{kg} / \mathrm{m}^{2}\right)$ & $26.0 \pm 3.9$ & $25.5 \pm 4.0$ & $0.656^{\mathrm{ns}}$ \\
\hline Waist circumference $(\mathrm{cm})$ & $97.9 \pm 9.0$ & $93.9 \pm 9.8$ & $0.139 \mathrm{~ns}$ \\
\hline $\begin{array}{l}\text { Systolic blood pressure } \\
(\mathrm{mm} \text { of } \mathrm{Hg})\end{array}$ & $129.8 \pm 16.9$ & $128.6 \pm 12.2$ & $0.774^{\mathrm{ns}}$ \\
\hline $\begin{array}{l}\text { Diastolic blood pressure } \\
(\mathrm{mm} \text { of } \mathrm{Hg})\end{array}$ & $80.2 \pm 7.8$ & $81.0 \pm 6.1$ & $0.688^{\mathrm{ns}}$ \\
\hline Platelet count ( x109/L) & $303.1 \pm 68.7$ & $327.8 \pm 66.8$ & $0.203^{\mathrm{ns}}$ \\
\hline $\begin{array}{l}\text { Fasting blood sugar } \\
(\mathrm{mmol} / \mathrm{L})\end{array}$ & $6.6 \pm 2.8$ & $5.9 \pm 2.2$ & $0.330 \mathrm{~ns}$ \\
\hline $\begin{array}{l}\text { Fasting blood sugar after } \\
2 \text { hour }(\mathrm{mmol} / \mathrm{L})\end{array}$ & $10.0 \pm 4.2$ & $9.1 \pm 4.7$ & $0.478^{\mathrm{ns}}$ \\
\hline Total cholesterol (mg/dL) & $210.0 \pm 48.7$ & $199.9 \pm 38.4$ & $0.419 \mathrm{~ns}$ \\
\hline $\mathrm{LDL}(\mathrm{mg} / \mathrm{dL})$ & $126.0 \pm 40.5$ & $119.6 \pm 36.7$ & $0.561^{\mathrm{ns}}$ \\
\hline $\mathrm{HDL}(\mathrm{mg} / \mathrm{dL})$ & $40.7 \pm 9.1$ & $36.6 \pm 8.9$ & $0.113^{\text {ns }}$ \\
\hline $\mathrm{TG}(\mathrm{mg} / \mathrm{dL})$ & $209.0 \pm 95.9$ & $222.8 \pm 116.2$ & $0.649 \mathrm{~ns}$ \\
\hline AST (U/L) & $55.2 \pm 30.1$ & $33.6 \pm 20.0$ & $0.004^{\mathrm{s}}$ \\
\hline $\operatorname{ALT}(\mathrm{U} / \mathrm{L})$ & $97.0 \pm 51.5$ & $55.5 \pm 28.6$ & $0.001^{s}$ \\
\hline AST/ALT & $0.6 \pm 0.2$ & $0.7 \pm 0.3$ & $0.171^{\mathrm{ns}}$ \\
\hline HOMA-IR & $2.4 \pm 1.9$ & $2.3 \pm 1.6$ & $0.841^{\mathrm{ns}}$ \\
\hline GGT (U/L) & $73.6 \pm 48.6$ & $49.9 \pm 25.4$ & $0.035^{\mathrm{s}}$ \\
\hline Serum ferritin $(\mu \mathrm{g} / \mathrm{L})$ & $139.4 \pm 124.5$ & $103.5 \pm 69.9$ & $0.214^{\mathrm{ns}}$ \\
\hline
\end{tabular}

Table II

Platelet count and APRI of study patients in two groups

\begin{tabular}{|lcr|c|}
\hline Variables & $\begin{array}{c}\text { Non-alcoholic steatohepa- } \\
\text { titis } \\
(\mathrm{n}=25)\end{array}$ & $\begin{array}{c}\text { Simple steatosis } \\
(\mathrm{n}=25)\end{array}$ & P value \\
\hline Platelet count & Mean \pm SD & Mean \pm SD & \\
APRI & $303.1 \pm 68.7$ & $327.8 \pm 66.8$ & $0.203^{\text {ns }}$ \\
Data are mean \pm SD & $0.5 \pm 0.3$ & $0.3 \pm 0.2$ & 0.009 s \\
\hline
\end{tabular}

\section{Discussion}

Non-alcoholic fatty liver disease has been shown to be independently associated with increased overall, liver-related and cardiovascular mortality.22 Although the liver-related but not cardiovascular, mortality is higher in patients with non-alcoholic steatohepatitis compared with simple steatosis..22 It is suggesting that progressive liver disease is mostly confined to non-alcoholic steatohepatitis.
This study showed that APRI was significantly higher in the non-alcoholic steatohepatitis group than in the simple steatosis group. In this study, APRI was used to measure and compare with nonalcoholic fatty liver disease activity score and to overcome the diffculty, limitations, and complications of liver biopsy.

The simple and realistic method of APRI as a promising predictor was evaluated for usefulness in measuring liver fibrosis. $\underline{.23-25}$

APRI has been used in the evaluation of patients with alcoholic liver fibrosis, chronic hepatitis B and chronic hepatitis $\mathrm{C}$ with high accuracies. $\underline{26}$

APRI had a better result as a serologic test indicating liver fibrosis than aspartate aminotransferase to alanine aminotransferase ratio (AAR) for chronic hepatitis B patients. $\underline{27}$

So, it is suggested that APRI was correlated with non-alcoholic fatty liver disease activity score.

\section{Conclusion}

The APRI score was significantly higher in the nonalcoholic steatohepatitis group than simple steatosis group. So, AST to platelet ratio index can be used as a non-invasive marker for the diagnosis of nonalcoholic steatohepatitis in non-alcoholic fatty liver disease patients.

\section{Ethical Issue}

Ethical clearance for the study was taken from the Institutional Review Board of the Bangabandhu Sheikh Mujib Medical University prior to the commencement of this study. Approval paper was given by $75^{\text {th }}$ Institutional Review Board, Bangabandhu Sheikh Mujib Medical University, meeting held on $30^{\text {th }}$ November 2014 (No. BSMMU/2014/13573).

\section{Conflict of Interest}

Authors declare no conflict of interest.

\section{References}

1. Eckel RH, Grundy SM, Zimmet PZ. The metabolic syndrome. Lancet 2005; 365: 1415-28.

2. Adams LA, Talwalkar JA. Diagnostic evaluation of nonalcoholic fatty liver disease. J Clin Gastroenterol. 2006; 40: 34-38.

3. Andrea ER. Non-alcoholic fatty liver disease. In: Sleisenger and Fordtran's Gastrointestinal and liver disease: Pathophysiology, diagnosis and management. Mark F, Lawrence SF, Lawrence JB, (eds). 9th 
ed. Philadelphia, Elsevier, 2010, pp 1401-13.

4. Pasumarthy L, Srour J. Non-alcoholic steatohepatitis: A review of the literature and updates in management. South Med J. 2010: 103: 547-50.

5. Jain KA, McGahan JP. Spectrum of CT and sonographic appearance of fatty infiltration of the liver. Clin Imaging. 1993; 17: 162-68.

6. Angulo P, Keach JC, Batts KP, Lindor KD. Independent predictors of liver fibrosis in patients with non-alcoholic steatohepatitis. Hepatology 1999; 30: 1356-62.

7. Angulo P, Hui JM, Marchesini G. The NAFLD fibrosis score: A noninvasive system that identifies liver fibrosis in patients with NAFLD. Hepatology 2007; 45: 846-54.

8. Annurad E, Shiwaku K, Nogi A, Kitajima K, Enkhmaa B, Shimono K, Yamane Y. The new BMI criteria for Asians by the Regional Office for the Western Pacific Region of WHO are suitable for the screening overweight to prevent metabolic syndrome in elder Japanese Workers. J Occup Health. 2003; 45: 335-43.

9. Pulzi FBU, Cisternas RM, Murilo RR, Cristiane MF, Malheiros CA, Salles JE. New clinical score to diagnose non-alcoholic steatohepatitis in obese patients. Diabetol Metab Syndr. 2011; 3: 3-8.

10. Alam S, Alam SMN, Chowdhury ZR, Alam M, Kabir J. Non-alcoholic steatohepatitis in nonalcoholic liver disease patients of Bangladesh. World J Hepatol. 2013; 5: 281-87.

11. Ioannou GN, Boyko EJ, Lee SP. The prevalence and predictors of elevated serum aminotransferase activity in the United States in 1999-2002. Am J Gastroenterol. 2006; 101: 76-82.

12. Argo CK, Northup PG, Al-Osaimi AM, Caldwell $\mathrm{SH}$. Systematic review of risk factors for fibrosis progression in non-alcoholic steatohepatitis. J. Hepatol. 2009; 51: 371-79.

13. Bayard M, Holt J, Boroughs E. Non-alcoholic fatty liver disease. Am Fam Physician. 2006; 73: 1961-68.

14. Bellentanis S, Scaglioni F, Marinom, Bedogni G. Epidemiology of non-alcoholic fatty liver disease. Dig Dis. 2010; 28: 155-61.

15. Mawatari H, Yoneda M, Kirikoshi H, Maeda S, Nakajima A, Saito S. Thrombocytopenia is more severe in patients with chronic hepatitis $C$ than in patients with non-alcoholic fatty liver disease. J Gastroenterol. 2012; 47: 606-07.

16. Wai CT, Greenson JK, Fontana RJ, Kalbfleisch JD, Marrero JA, Conjeevaram HS, Lok AS. A simple noninvasive index can predict both significant fibrosis and cirrhosis in patients with chronic hepatitis C. Hepatology 2003; 38: 518-26.

17. Sterling RK, Lissen E, Clumeck N, Sola R, Correa MC, Montaner J, S. Sulkowski M, Torriani FJ,
Dieterich DT, Thomas DL, Messinger D. Development of a simple noninvasive index to predict significant fibrosis in patients with $\mathrm{HIV} / \mathrm{HCV}$ coinfection. Hepatology 2006; 43: 1317-25.

18. Shah AG, Lydecker A, Murray K, Tetri BN, Contos MJ, Sanyal AJ, Nash Clinical Research Network. Comparison of noninvasive markers of fibrosis in patients with nonalcoholic fatty liver disease. Clin Gastroenterol Hepatol. 2009; 7: 1104-12.

19. Caldwell SH, Argo CK. Non-alcoholic Fatty Liver Disease and Nutrition. In: Sherlock's Diseases of the liver and biliary system. Dooley JS, Lok ASF, Burroughs AK, Heathcote EJ (eds). 12th ed. West Sussex, Wiley-Blackwell, 2011, pp 546-67.

20. Kleiner DE, Brunt EM, Van Natta M, Behling C, Contos MJ, Cummings OW, Ferrell LD, Liu YC, Torbenson MS, Unalp-Arida A, Yeh M. Design and validation of a histological scoring system for nonalcoholic fatty liver disease. Hepatology 2005; 41: 1313-21.

21. Askgaard G, Leon DA, Kjaer MS, Deleuran T, Gerds TA, Tolstrup JS. Risk for alcoholic liver cirrhosis after an initial hospital contact with alcohol problems: A nationwide prospective cohort study. Hepatology 2017; 65: 929-37.

22. Musso G, Gambino R, Cassader M, Pagano G. Meta -analysis: Natural history of non-alcoholic fatty liver disease (NAFLD) and diagnostic accuracy of non-invasive tests for liver disease severity. Ann Med. 2011; 43: 617-49.

23. Loaeza-del-Castillo A, Paz-Pineda F, OviedoCardenas E, Sanchez-Avila F, Vargas-Vorackova F. AST to platelet ratio index (APRI) for the noninvasive evaluation of liver fibrosis. Ann Hepatol. 2008; 7: 350-57.

24. Shin WG, Park SH, Jang MK, Hahn TH, Kim JB, Lee MS, Kim DJ, Jun SY, Park CK. Aspartate aminotransferase to platelet ratio index (APRI) can predict liver fibrosis in chronic hepatitis B. Dig Liver Dis. 2008; 40: 267-74.

25. Borsoi Viana MS, Takei K, Collarile Yamaguti DC, Guz B, Strauss E. Use of AST platelet ratio index (APRI score) as an alternative to liver biopsy for treatment indication in chronic hepatitis C. Ann Hepatol. 2009; 8: 26-31.

26. Lin CS, Chang CS, Yang SS, Yeh HZ, Lin CW. Retrospective evaluation of serum markers APRI and AST/ALT for assessing liver fibrosis and cirrhosis in chronic hepatitis B and C patients with hepatocellular carcinoma. Intern Med. 2008; 47: 569 -75 .

27. Sim SJ, Cheong JY, Cho SW, Kim JS, Lim TY, Shin DH, Lim SG, Kim YB, Lee KM, Yoo BM, Lee KJ. Efficacy of AST to platelet ratio index in predicting severe hepatic fibrosis and cirrhosis in chronic hepatitis B virus infection. Korean J Gastroenterol. 2005; 45: 340-47. 